DOI : 10.31357/fhssphd.2013.00729

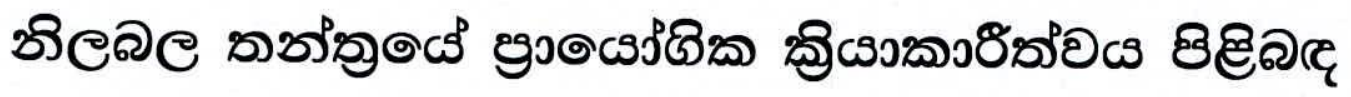

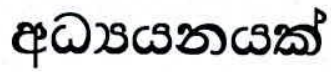

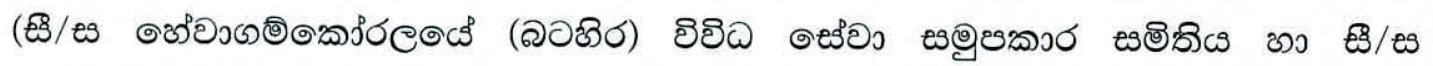

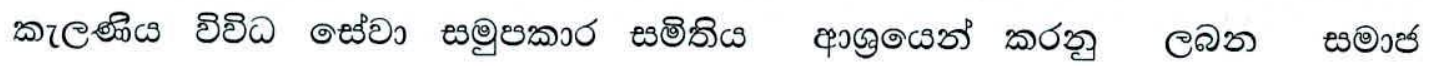

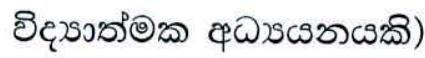

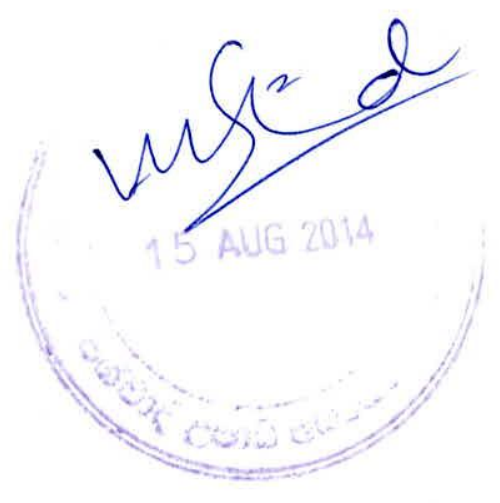

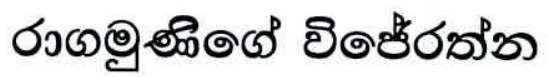

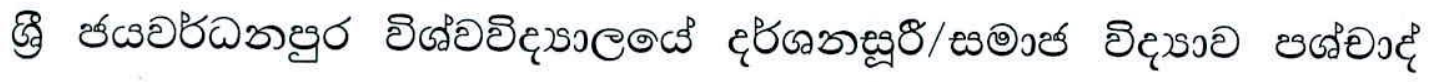

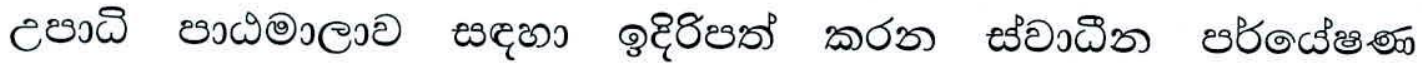
หิ่อรดตผ

2013.02.05 


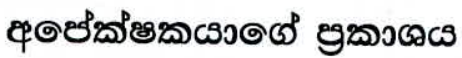

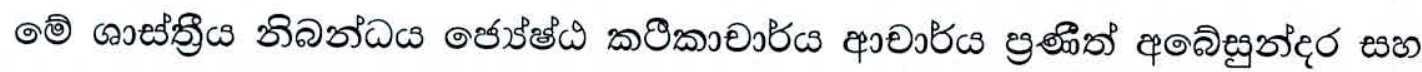

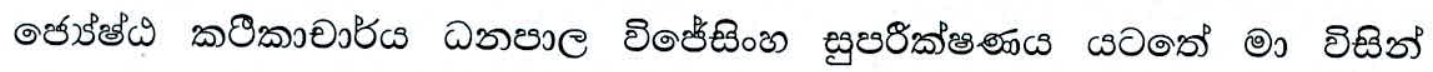

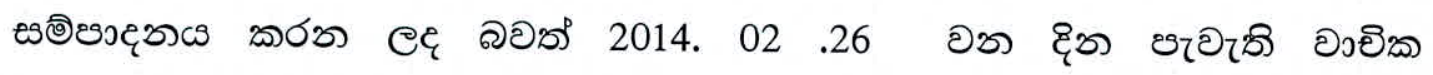

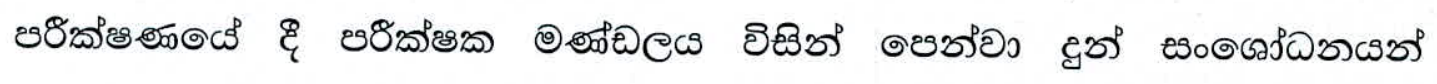

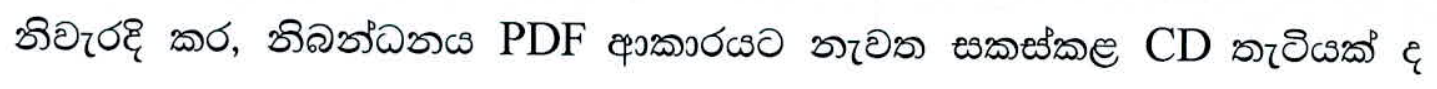

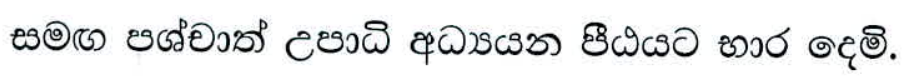

Eas $15 / 08 / 2014$

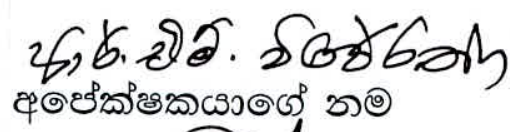

crsiess

రిఱుయ ఢాంచి: GS/Ph.D/SOC/3351/08 


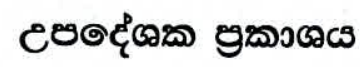

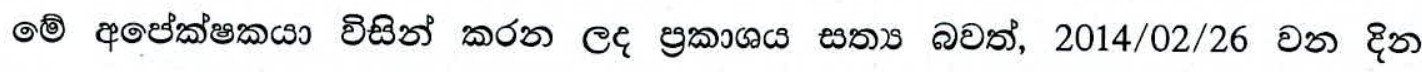

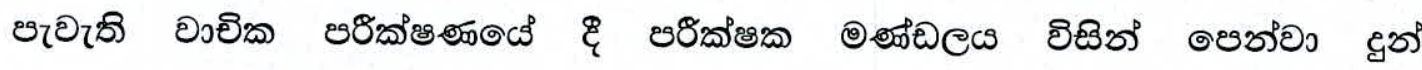

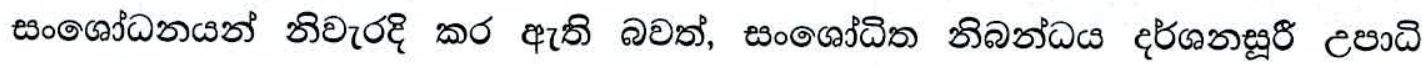

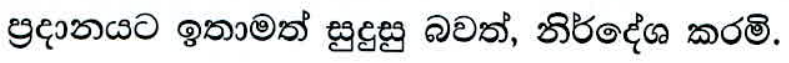

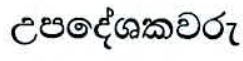

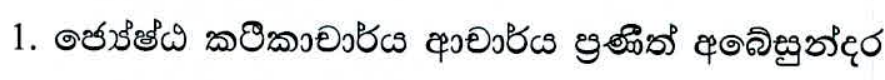

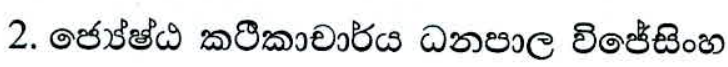

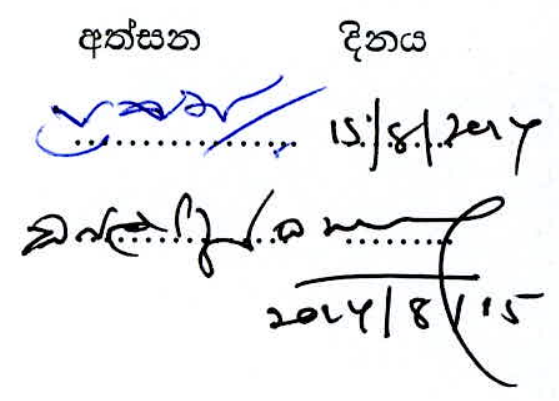




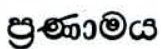

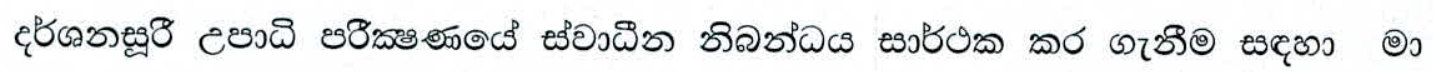

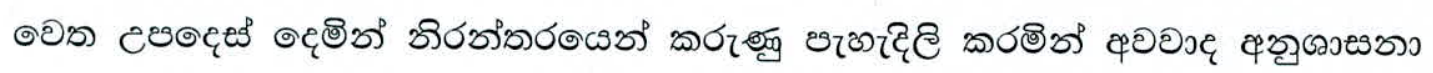

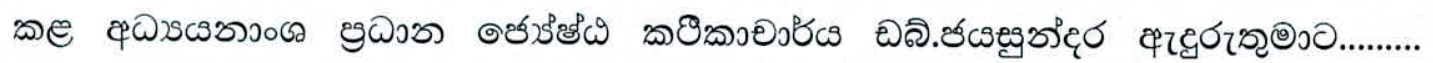

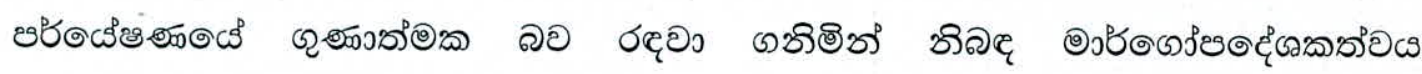

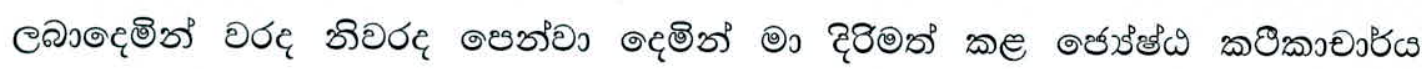

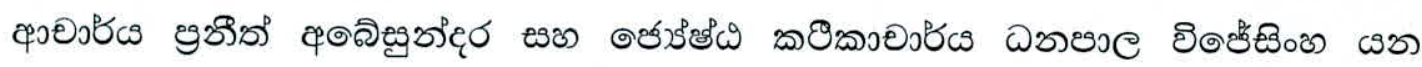

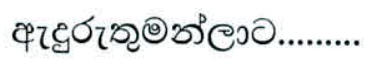

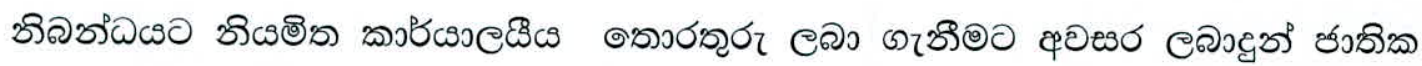

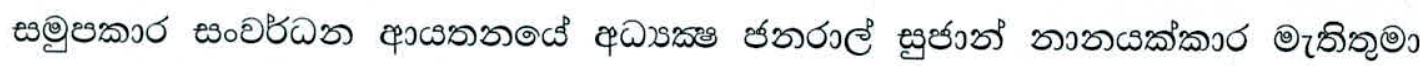

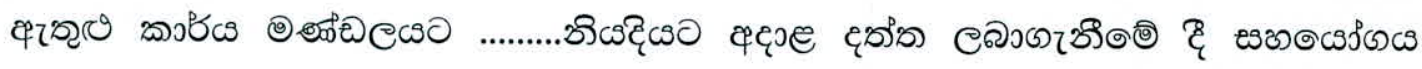

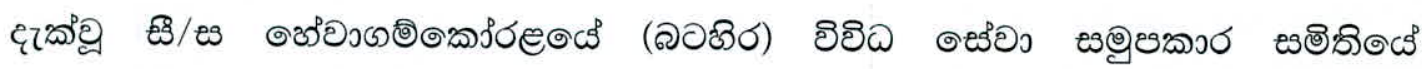

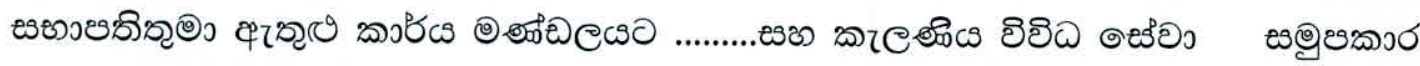

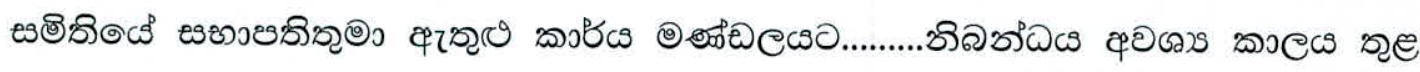

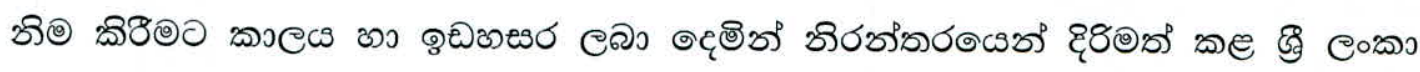

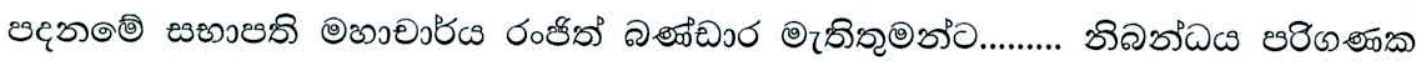

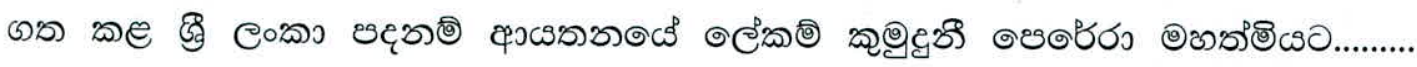

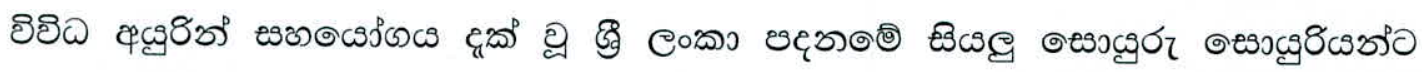

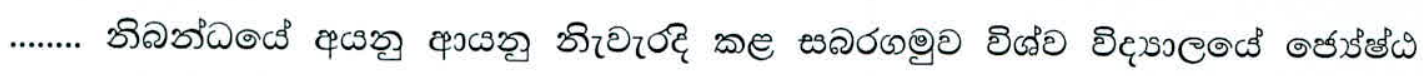

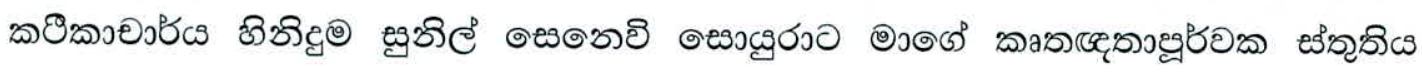
ชిร๑తి. 


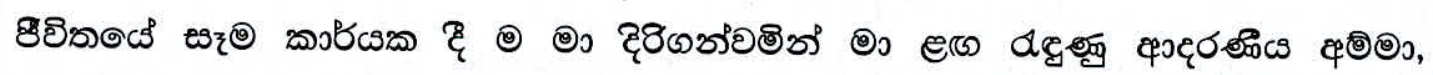

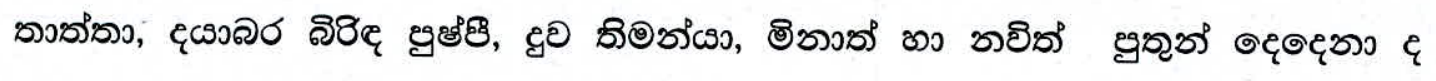

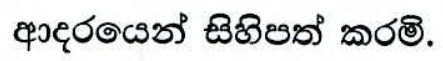


ஐอุร

8อุอ

ชवุต

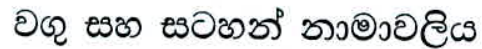

V-VI

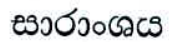

VII-IX

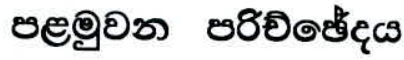

1.1 ऊદిรాలిఠ $1-7$

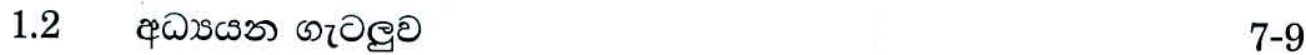

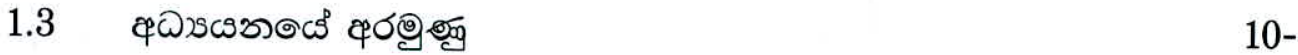

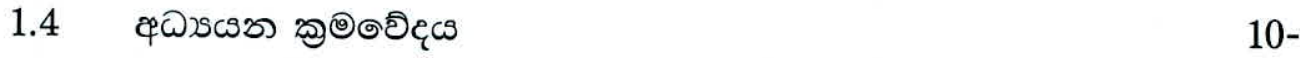

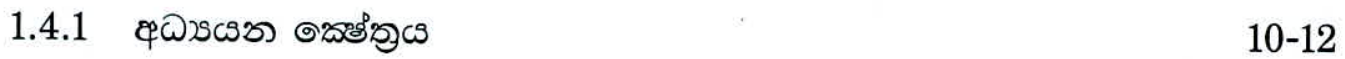

1.4.2 ऊิตిఁ̨ి $12-13$

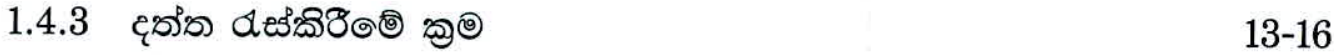

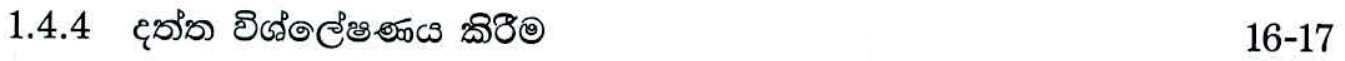

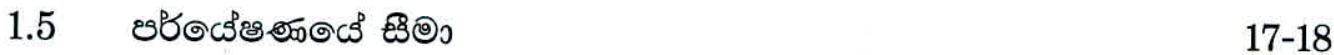

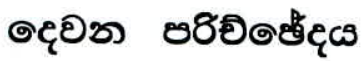

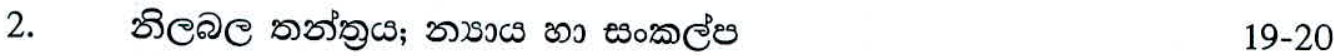

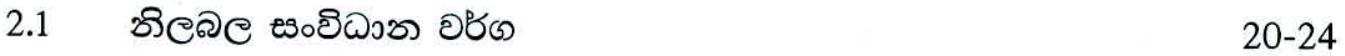

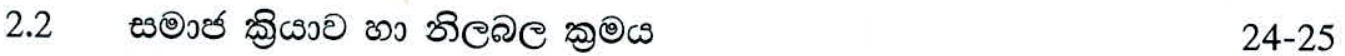

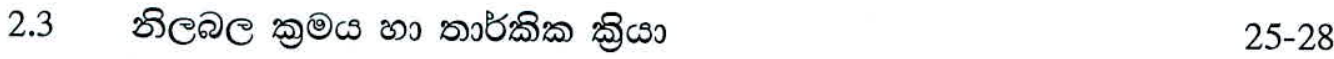

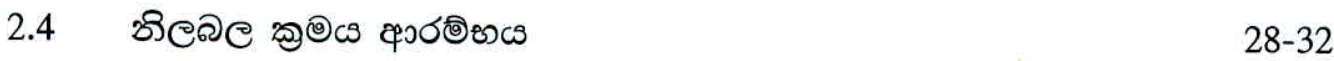




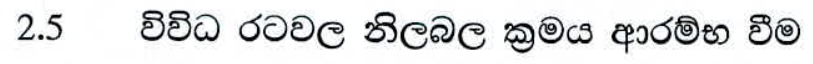

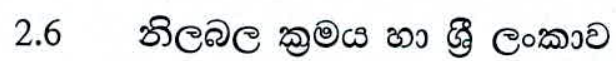

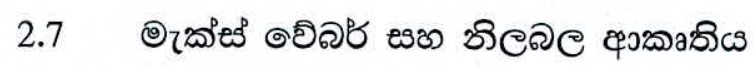

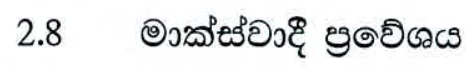

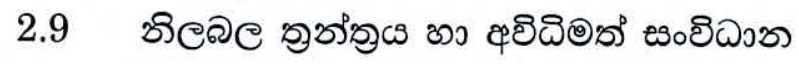
70-78

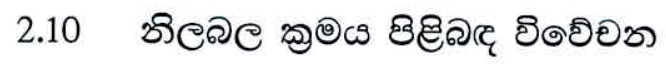
$78-91$

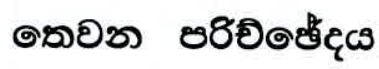

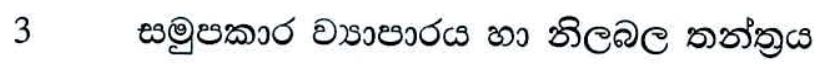

92

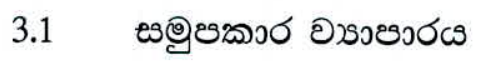

92-105

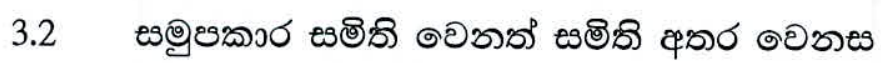
106-109

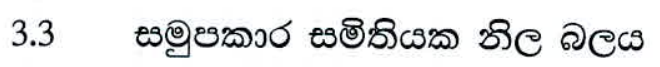
$110-111$

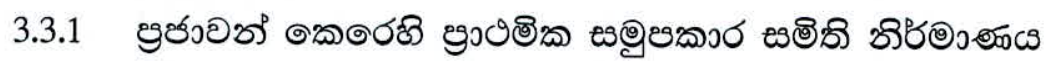
111-112

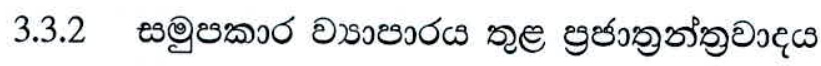
112-115

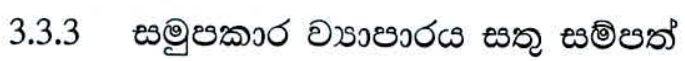

115-118 


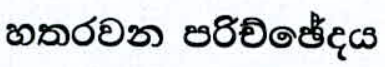

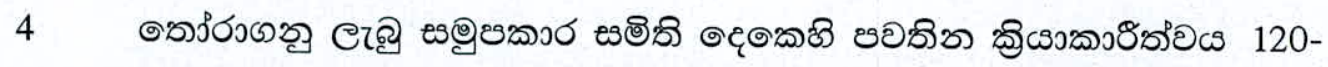

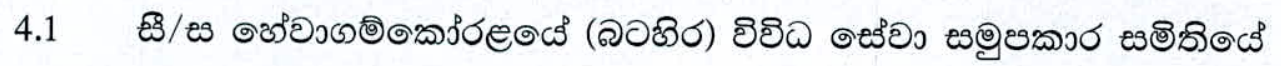

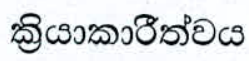

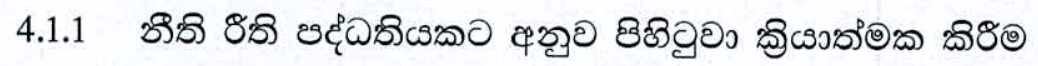
$121-123$

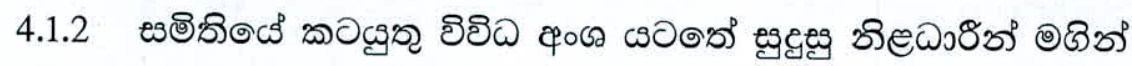

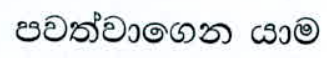

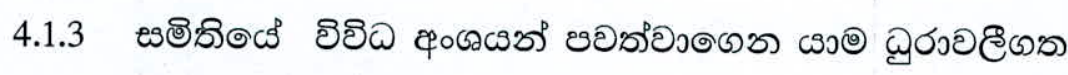

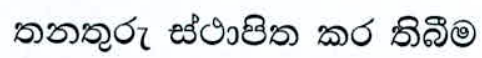

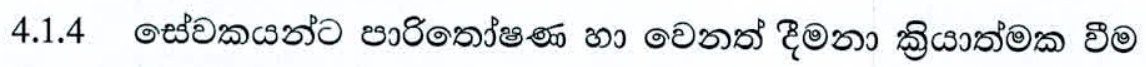
$129-123$

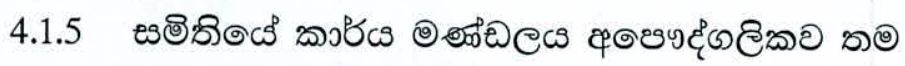

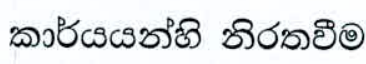

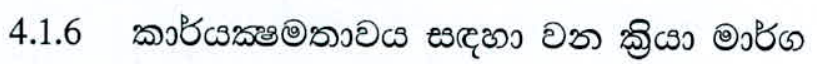
$131-135$

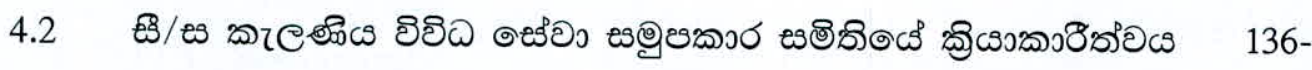

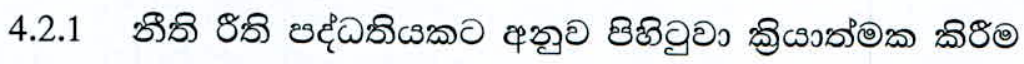

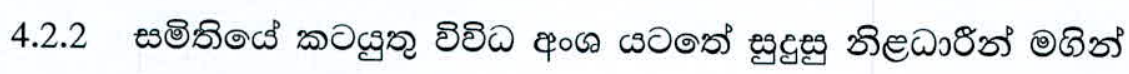
ชอรองดตร ผงอ $137-138$

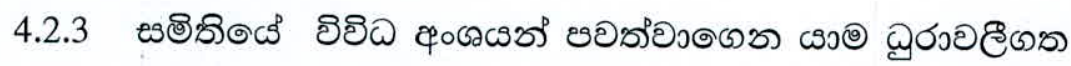

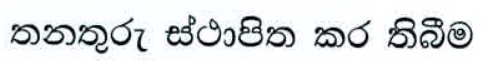
$138-142$

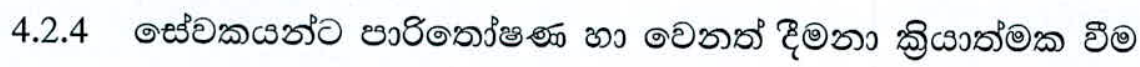
$142-143$ 


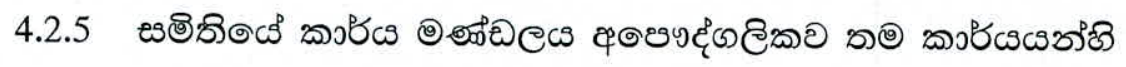
ริธุอึอ

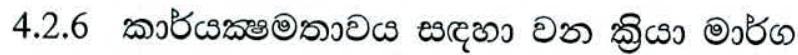

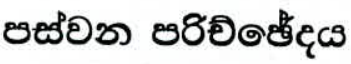

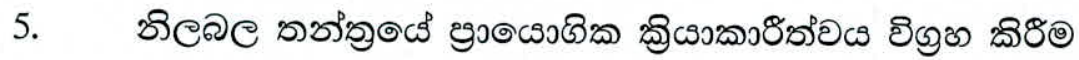

147-

5.15

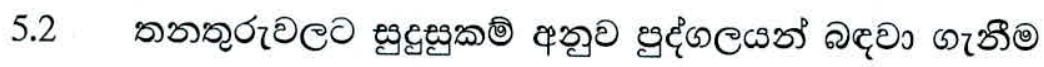

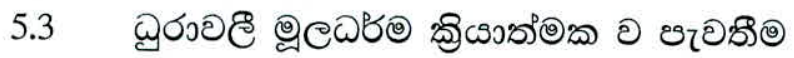

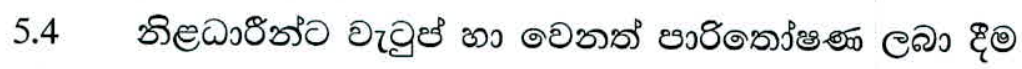
162-164

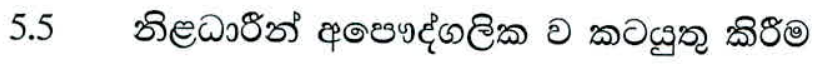

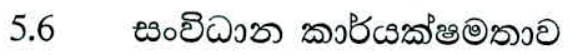

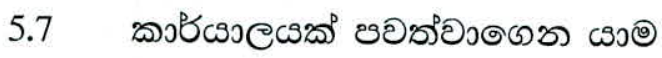

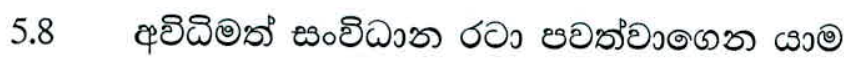
181-186

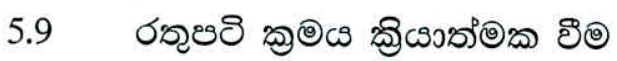
186-188

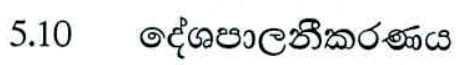
188-191

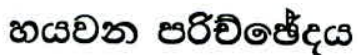

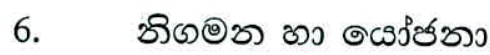

$192-$

6.1 भิต๑๐

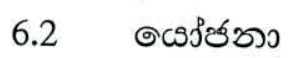




\section{อต అఅอతిద}

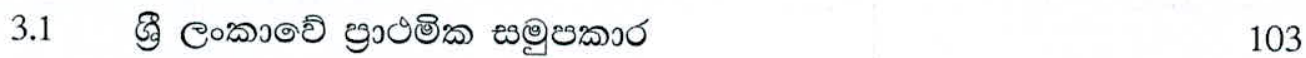

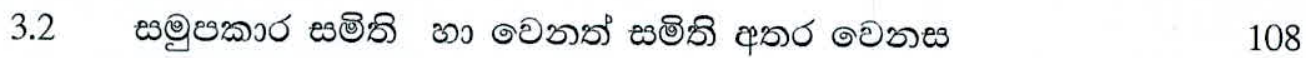

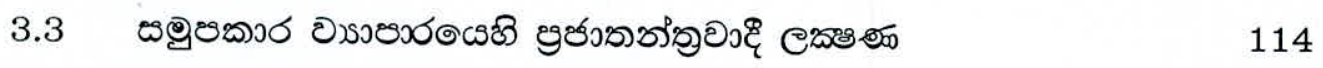

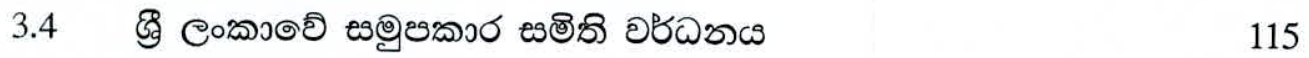

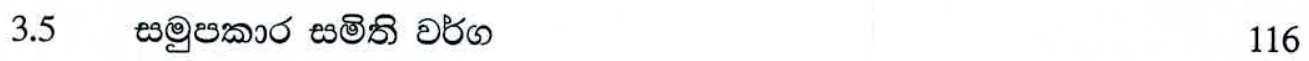

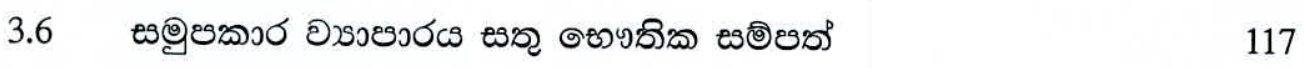

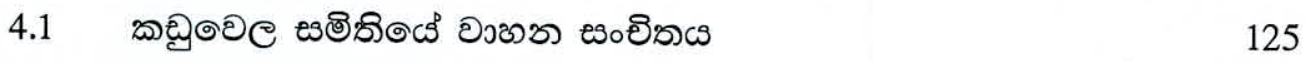

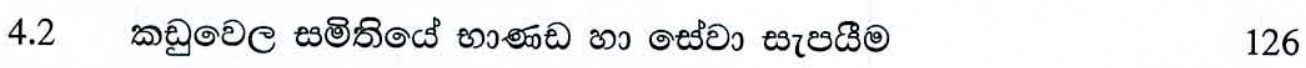

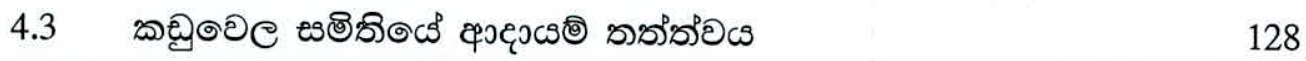

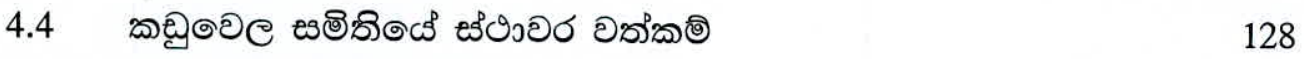

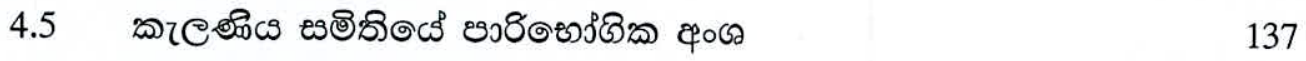

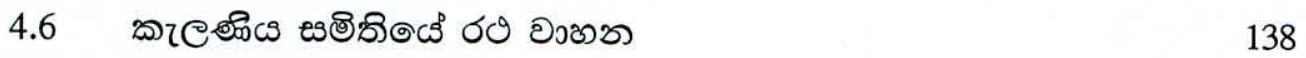

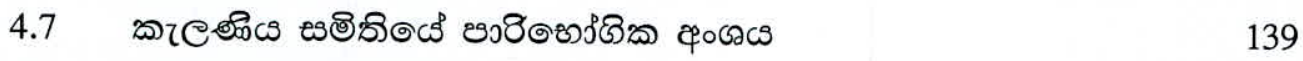

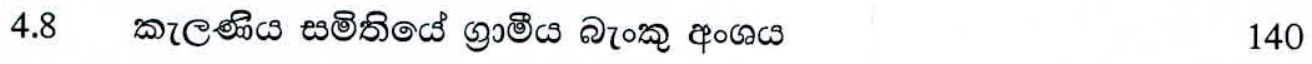

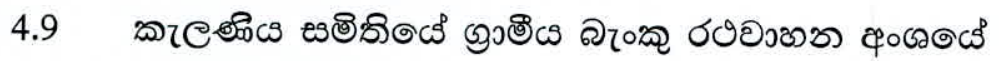

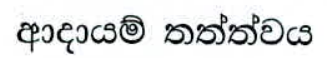




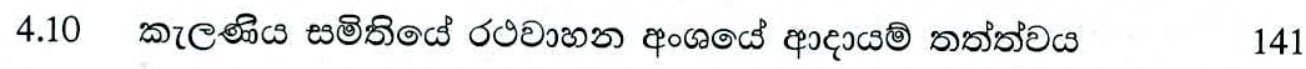

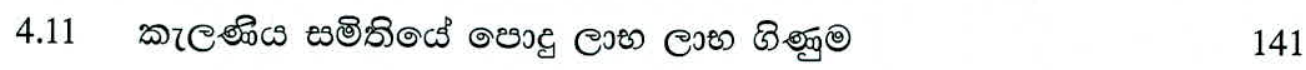

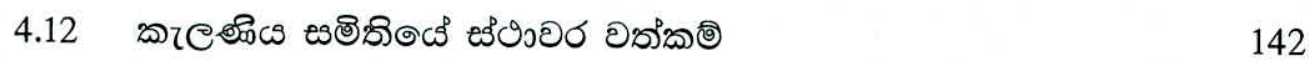

5.1 ผ

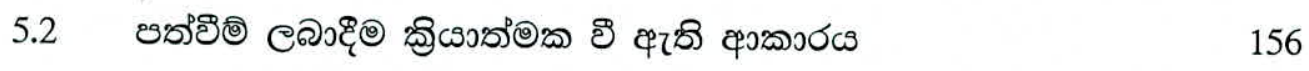

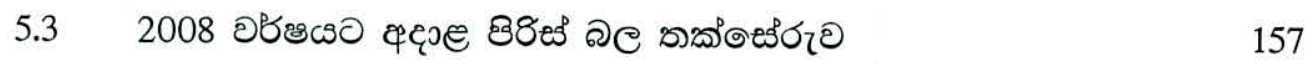

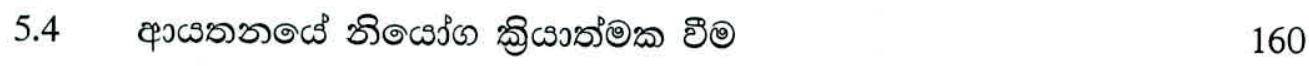

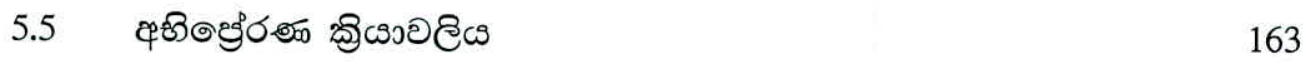

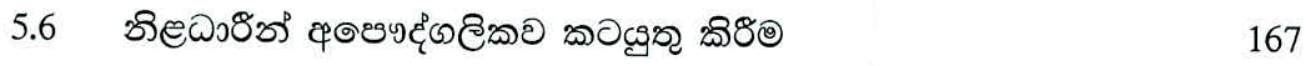

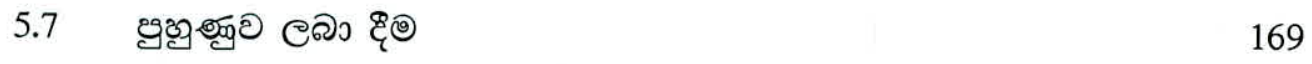

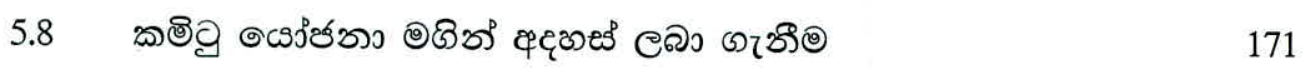

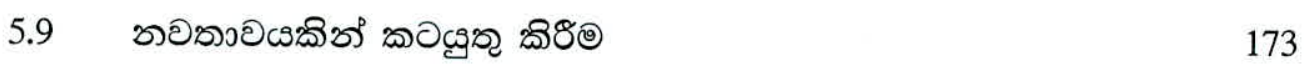

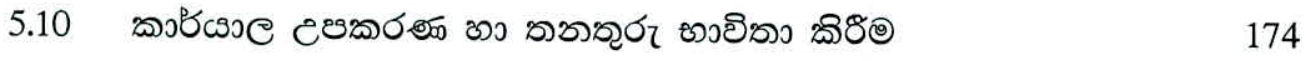

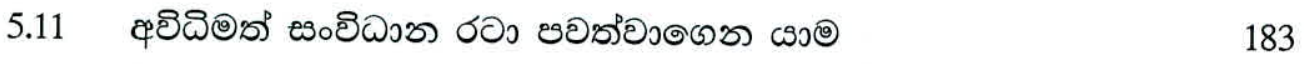

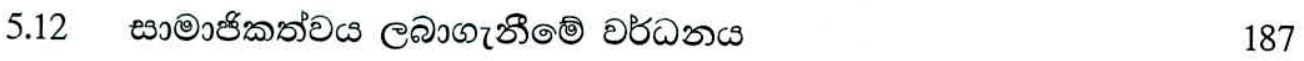

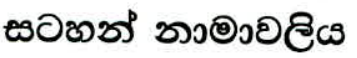

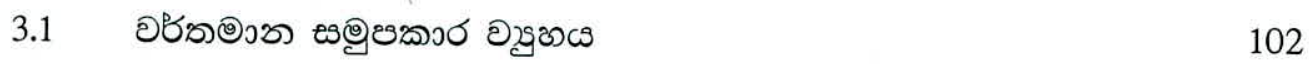

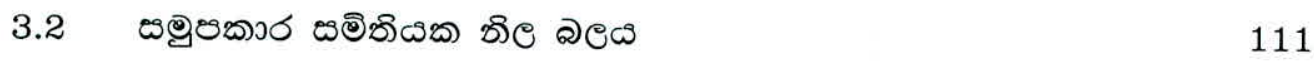

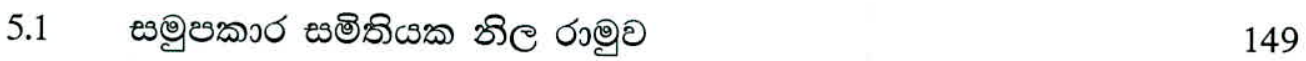




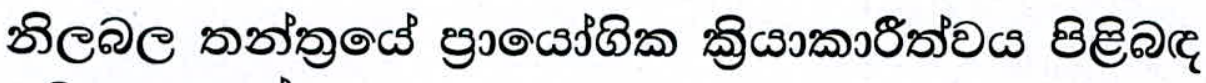

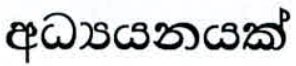

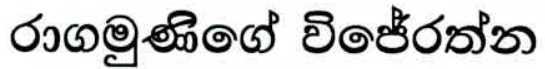

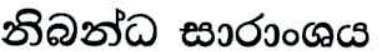

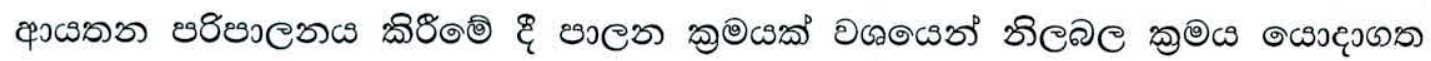

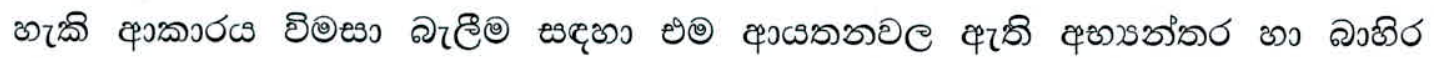

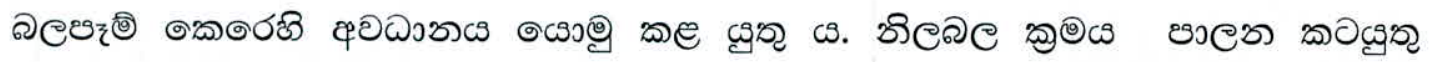

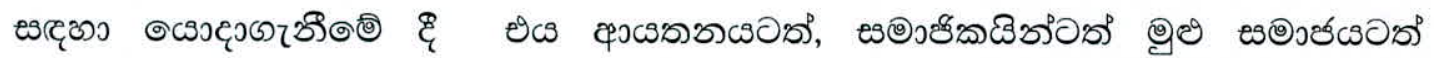

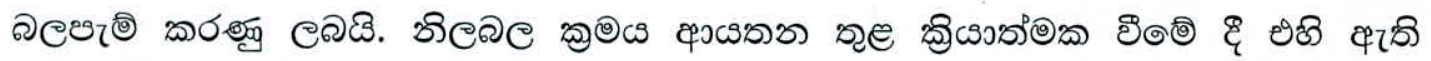

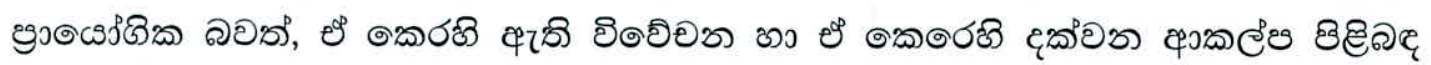

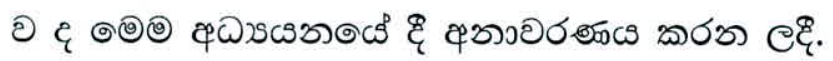

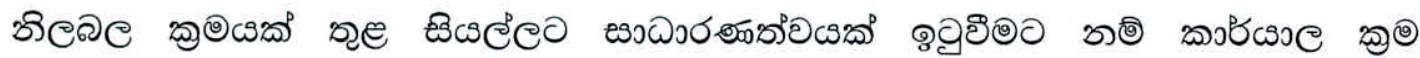

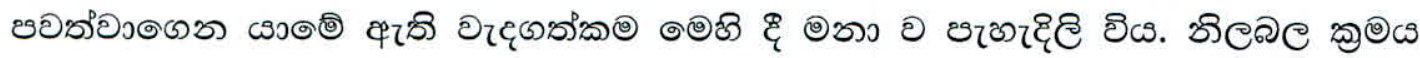

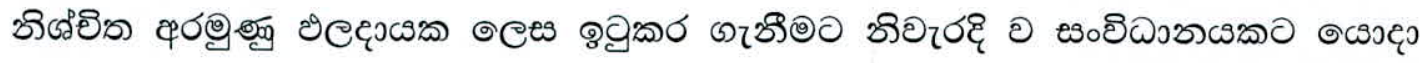

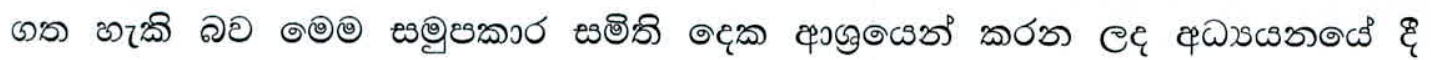

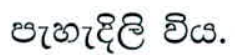




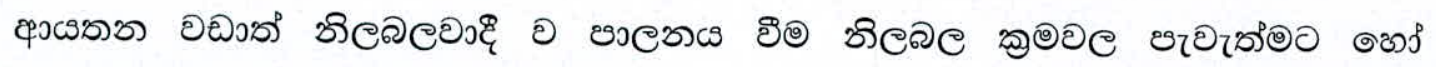

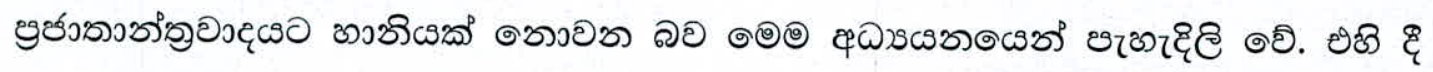

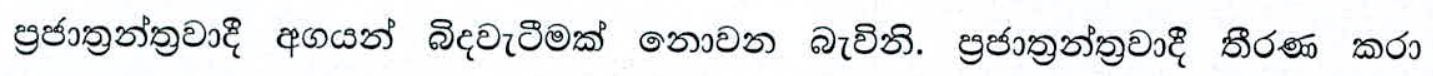

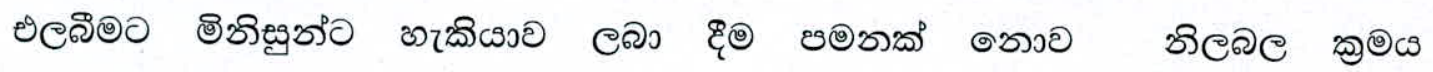

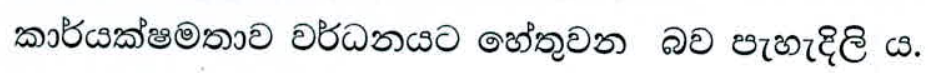

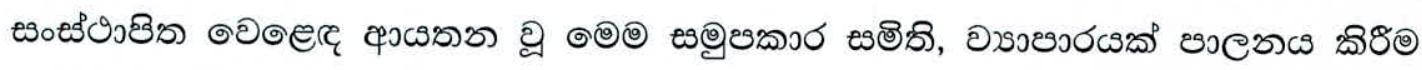

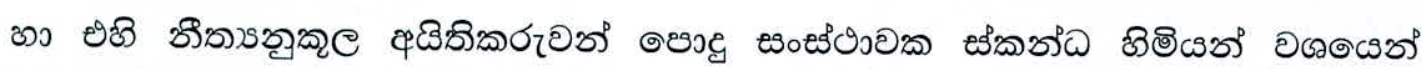

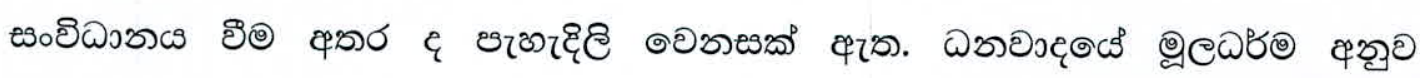

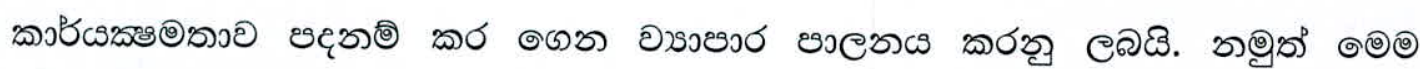

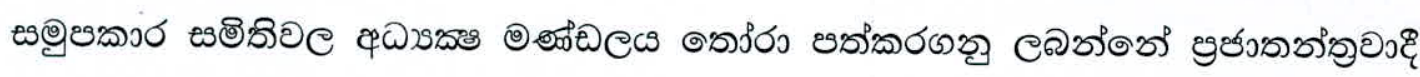

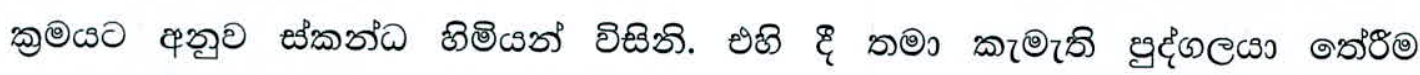

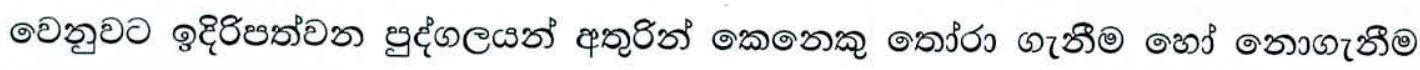

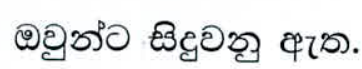

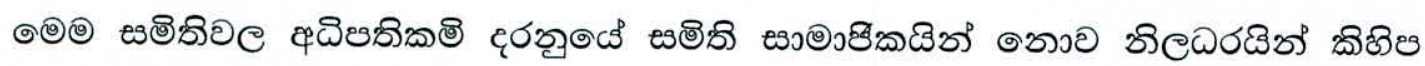

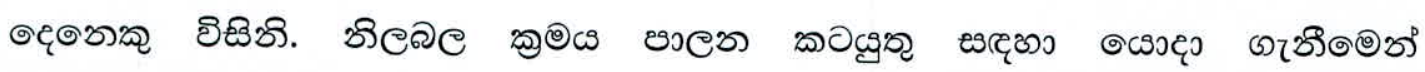

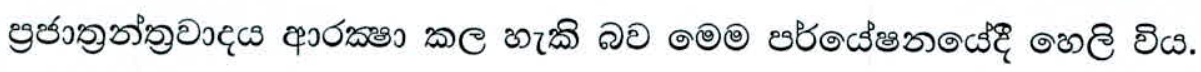




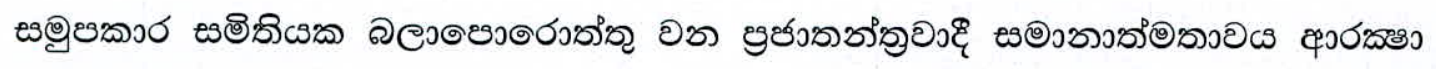

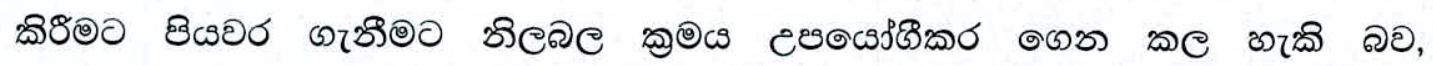

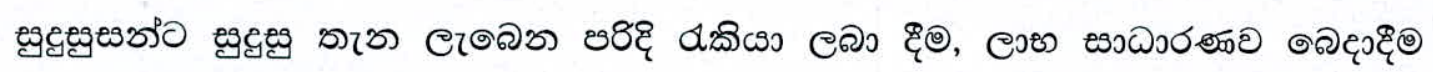

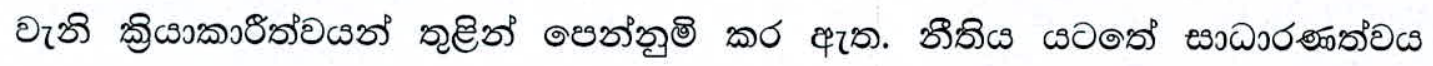

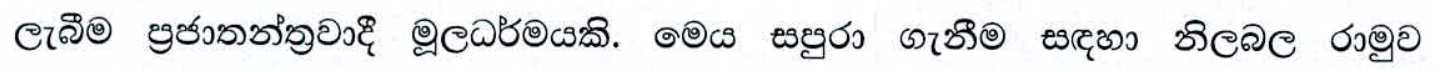

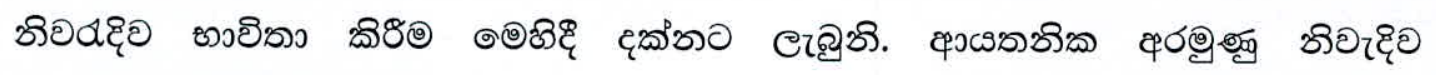

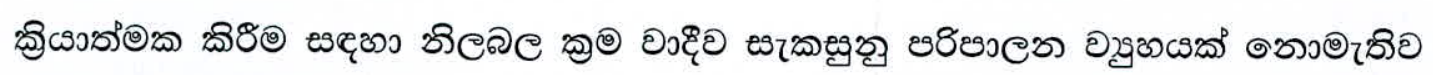

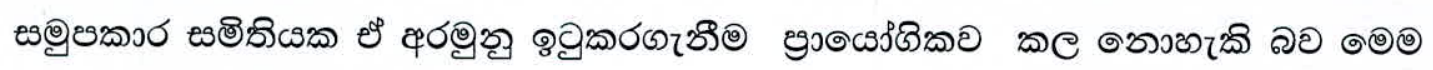

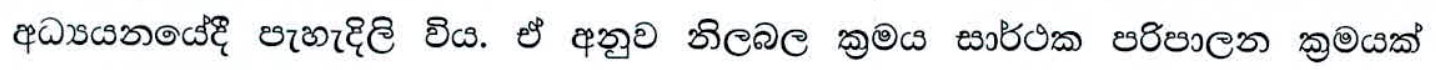

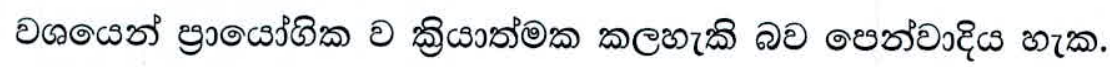




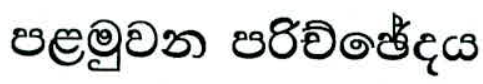

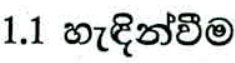

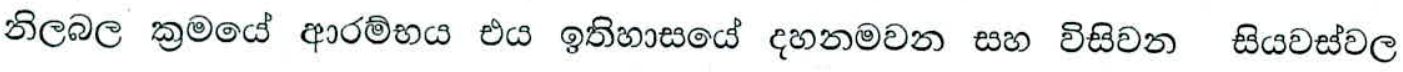

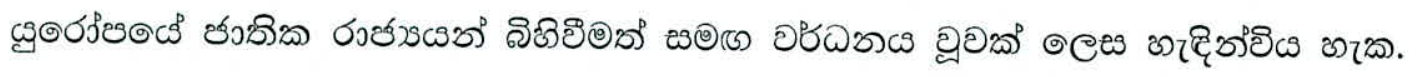

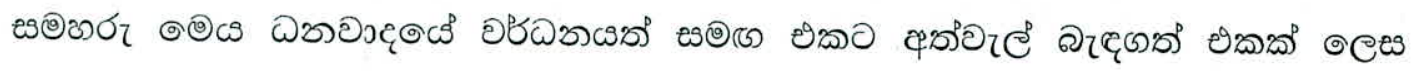

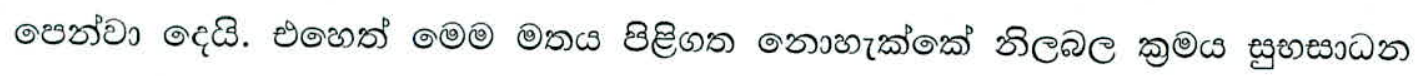

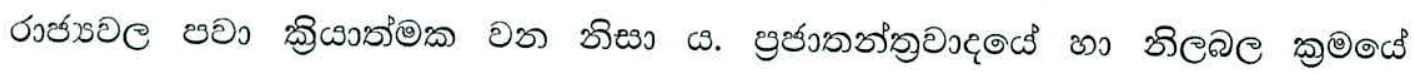

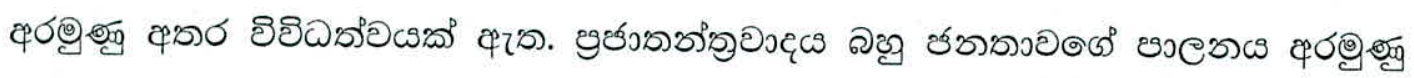

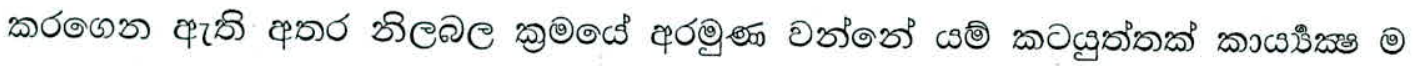

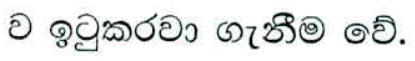

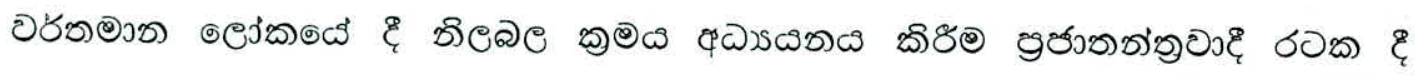

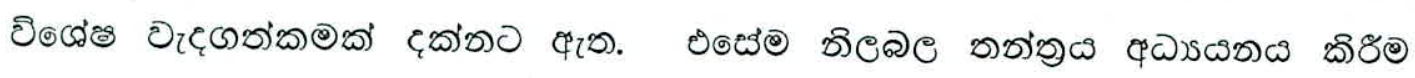

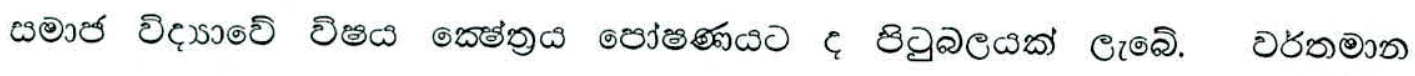

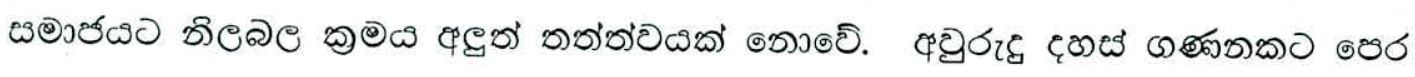

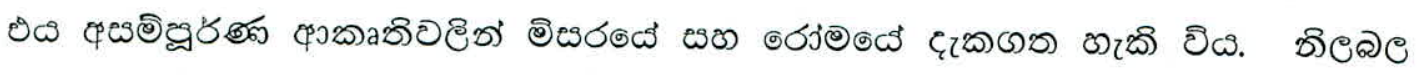

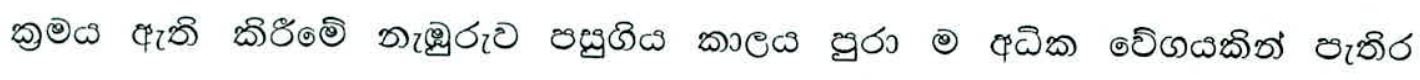

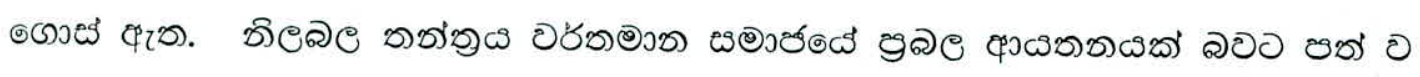

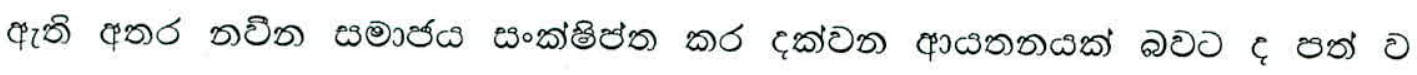

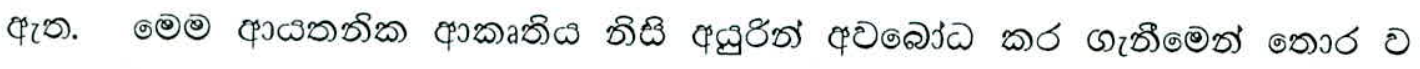

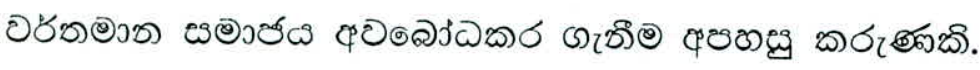

